\title{
Discussion on Relation between Human Capital Investment and Economic Growth of Enterprises
}

\author{
Pengzhen $\mathrm{Cai}^{1, \mathrm{a}^{*}}$ \\ ${ }^{1}$ School of economics, Sichuan University, Chengdu, Sichuan Province, China \\ a2572458883@qq.com
}

Keywords: Human capital; Economic growth of enterprises; Relation

\begin{abstract}
The market environment in China has changed greatly with the economic globalization. Human capital becomes a factor of economic growth of enterprises. It is extremely urgent to upgrade the industrial structure on the basis of sustainable development of enterprises and in a background where extensive economy is transformed into intensive economy. Under this background, the competition among enterprises starts to become talent competition. Enterprises with high-end talents can stand out in the fierce market competition. As a result, defining the relation between human capital and economic growth of enterprises is exactly defining future development of enterprises. The relation between human capital and economic growth of enterprises will be analyzed and discussed in the Paper.
\end{abstract}

\section{Introduction}

The most basic concept of western economics is human capital, which means investing certain capital to improve people's abilities. In terms of enterprises, enterprises are executors of human capital, the object of investment is employees, and the purpose of investment is to improve the employees' comprehensive abilities. In terms of domestic market, the international economy starts to recover with an optimistic development prospect. The national economy starts to be transformed into the real economy. Industrial structure is upgraded to give an impetus to development of innovation technology and make science and technology integrated into economy. The strategic policy of revitalizing the country through talent and science $\&$ technology is implemented thoroughly and meticulously in this way. However, since extensive economic growth mode has lasted for a long time in China, not only massive resources have been consumed, but also incomes of enterprises have not reached an expected level. Talent directly controls core technology and high-end market. Thus, China's enterprises shall adjust the industrial structure and comprehensively upgrade their informatization and industrialization, so as to make them invincible in the increasingly fierce market competition. In short, talent is a key factor for enterprises to carry out reform and innovation. Thus, the most effective way for enterprises to improve their core competitiveness is to invest in human capital. Only by improving importance attached by enterprises to talent can human resources be allocated optimally in a way that makes employees give full play to subjective initiative and push ahead with development of enterprises.

\section{Human Capital Investment Overview}

Investment refers to the process by which governments, enterprises, and individuals convert idle income into capital for the purpose of earnings. Human capital investment is also a type of investment. An economically developed country invests in education and citizen training, which is the definition of human capital investment in economics. Schultz believes that people have five kinds of abilities. All these five abilities can bring economic value. They are the ability to do things, the ability to learn, the ability to participate in activities, the ability of unbalanced state, and the ability to create. In terms of these five abilities, it is difficult to measure their roles played in production efficiency. In terms of human capital, investment activities are carried out on the basis of 
differentiation. People's comprehensive abilities are improved to a different extent for different investment activities. Thus, Schultz also holds human capital investment also includes investment in education, worker training, national immigration and other items and people's quality can be improved by investment. So-called human capital investment refers to enterprises' investment in employees in order to improve people's ability to obtain resources. Through investment, labor productivity can be increased and economic growth rapidly improved [1].

Subjects of human capital investment. Due to mechanism issues existing in China, enterprises are not highly attached to human capital investment. Thus, a dominant role of human capital investment is not fully presented. As subjects executing human capital investment, enterprises shall increase their initiative in investment and add more investment in human capital. Hence, the corresponding mechanism shall be established so as to be involved in the process of investment in human capital by enterprises and individuals make enterprises bear investment costs, form human capital in practical relation to enterprises' benefits, mobilize the initiative in enterprises' human capital, allow employees to give full play to subjective initiative, and improve the efficiency of enterprises' human capital investment[2].

\section{Characteristics of Human Capital Investment}

Compared with material capital investment, human capital investment is special. Specific special characteristics are as follow.

Actual effects of investment object. In an age of knowledge-based economy, the pace of development of science and technology is getting faster and faster. A replacement period for new product is increasingly shortened. Human is both subject and object of human capital investment. The reason is that different requirements are placed for human's physiological and psychological needs in different stage. Thus, investment must be made in the optimal stage of human's life in a way that gives play to effects of human capital investment to the greatest extent.

Specialness of investment object. Human capital investment is investment in human, or investor's ability in short. Thus, it is a nature of human resources investment. Human capital investment becomes a miscellaneous activity due to various impacts on specific human resources investment, as well as difference in family background, individual hobby and personality characteristics [3].

Purpose of investment subject. Driven by economic benefits, enterprises invest in employees in order to be able to obtain a steady stream of competitiveness in the market competition. Social and economic benefits are fulfilled in a better way.

Scale and long term of investment incomes. Human resources investment brings both multi-level incomes for enterprises and social benefits and plays a positive role in promoting social equality. Thus, social overall quality can be improved by improvement of overall social investment environment. However, knowledge accumulation is a long-term activity and requires good cognition. Thus, if human resources investment is decentralized, it is difficult to obtain high income.

Limited by social environment and human's psychological factors, human resources investment is irrevocable. And it takes a long time to obtain investment income, which is full of uncertainties.

Investment risk. From the perspective of scale and long term of investment, it can be seen easily that human resources investment is of high risk. Such risk originates from both market and individual. Human resources investment is unforeseeable and also influenced by its decision-making level and opportunity cost, making it difficult to revoke human resources investment and causing certain losses. Under this circumstance, in case of surplus net income in terms of human resources investment, there will be only one circumstance. That is, life and working time of investee have exceeded time of human resources investment. Rate of return cannot be calculated accurately in terms of human resources investment. Thus, human resources investment is highly risky [4]. 


\section{Role of Human Capital Investment in Economic Growth of Enterprises}

Improving labor productivity. The first element of means of production is human and human capital investment is an indispensible link of production. Enterprises are able to highly improve labor productivity by making human capital investment in a way that enhances their marginal benefit. That is, with the same means of production, total profits of enterprises will increase. After employees' quality and comprehensive abilities are improved, unnecessary wastes of enterprises can be reduced during production and utilization efficiency of energy and equipment improved. Besides, high-end talents of enterprises will be able to innovate in technologies in a way that enhances management level of enterprises [5].

Promoting enterprises to transform economic growth mode. In conventional business management, human capital investment has not attracted the attention of enterprises. However, as Demographic Dividend vanishes, labor shortage starts to occur in enterprises. Enterprises start to attach more importance to human capital investment. Making human capital investment can not only enhance management level and production benefit of enterprises, but also replace other incomes. Enterprises are able to obtain other economic benefits by human capital investment. Thus, human capital investment is able to drive enterprises to transform toward intensive economy and fulfill sustainable development [6].

\section{Relation between Human Capital Investment and Economic Growth of Enterprises}

Making human capital investment is an inevitable requirement for enterprises to be upgraded. With the development of economic globalization, the national economy starts to transform towards the real economy, and industrial transformation and enterprise upgrading starts to appear. Thus, if enterprises intend to be upgraded, technology and management mode shall be innovated and the strategy of revitalizing the country through talent and science \& technology shall be implemented.

However, China's enterprises are large-sized but not strong at present, which seriously hinders the economic growth of enterprises. When industry is strong enough, people will become wealthy and the country will become powerful. Thus, enterprises are required to re-plan the path of development. Due to long-term extensive economy, China's enterprises are always at a lower end of Smiling Curve, making people directly control market and technology. As a result, China's enterprises shall be upgraded and adjust the way of economic development as early as possible in a way that improves market competitiveness and becomes invincible in the increasingly fierce market competition.

Strengthening the value of human capital is the most critical factor for enterprises to be upgraded. Schwab said human capital would make more contribution because labor employment was squeezed due to formidable capitalist power. At present, in the economic environment of China, human capital investment is a key factor for enterprises to innovate. When the country adjusts human resources mix, enterprises may grasp development opportunity, innovate in their management mechanism, increase human capital investment, optimize investment structure, make the best use of everything to the greatest extent, urge employees to give full play to subjective initiative and improve their performance [7].

Economic growth of enterprises is a result of human capital accumulation. In terms of economic growth of enterprises, human capital is the most important factor with special production capacity. From the perspective of production, human capital is an indispensible input factor and a key to improving productivity for enterprises. Enterprises are able to improve both their own production efficiency and other production efficiency by making human capital investment. As an element of production, human resources are able to make direct contribution to economic growth of enterprises and also drive economic growth through science and technology. Advancements in science and technology are made by means of increase on human capital and are also a reason why benefits are increased by human capital. It can be seen that economic growth depends on advancements in science and technology and increase on human capital.

Robert - Lucas, a famous economist, accepted human capital as gaining knowledge through 
education. This is general. However, there is internal effect in human capital, namely contribution to investor's productivity. Specialized knowledge is gained during learning by doing and belongs to external effect, which can transfer human capital level and improve production efficiency and efficiency of material capital production. It can be seen from external effect of human capital that economic growth of enterprises is a result of human capital during constant accumulation. In a nutshell, human capital is driving force of economic growth of enterprises [8].

\section{How to Strengthen Human Capital Investment, and Promote Economic Growth of Enterprises}

Human knowledge and manpower are the power to realize growth, professional human capital and knowledge can cause increasing income, and other incomes can be obtained at the same time in new economic growth theory. Under the development background for current stage of China, enterprises shall pay attention to development and accumulation of human capital, and increase investment strength to improve economic benefit of enterprises, let employees comprehensively develop, and promote enterprises to realize sustainable development[9].

Transform thoughts and ideas. At present, most enterprises only emphasize the importance of material investment to enterprises, and overlooks human capital investment. Therefore, enterprise managers shall firstly transform thoughts and ideas, improve the emphasis degree to human capital investment, and deeply understand the relation between human capital investment and economic growth. They shall coordinate relation between human investment and material investment, and pay attention to thought education investment of enterprise managers and employees to continuously and steadily conduct human capital investment.

Action is oriented at ideas. At present, enterprises in China are weak in human capital investment. Therefore, in order to solve this problem, it can be started from the capital concept of enterprises to make enterprise employees and managers deeply realize the importance to improve comprehensive ability and accomplishment. Enterprise accountants shall guarantee that there is human capital investment every year, there is specific investment plan, and corresponding investment shall be conducted according to plan[10].

Conduct employee training. For strength of Chinese enterprises to human capital investment is small, it causes that overall quality and comprehensive ability of employees are not very high. Therefore, employee training shall be conducted. Think band of employees shall be updated thought morals, professional skill and code of conduct etc. to continuously improve their working accomplishments and skills. At the time of conducting specific employee training, training shall be conducted according to operating posts, difficult levels, work natures and responsibility requirements etc.. At the same time, employees shall be assessed to make training results able to be related to salary and promotion for employees. The enthusiasm of employees shall be fully aroused to promote them to exert subjective initiative and make comprehensive ability and professional skill for enterprise employees continuously improved.

Human capital investment is the necessity to conduct modern management, so enterprises shall fully arouse enthusiasm of employees. At present, the overall quality of Chinese human capital is relatively low, which shows that enterprises not only need to strengthen investment strength of human capital, and shows that human capital has a great potential role on economic growth. In this the era of knowledge-driven economy, a win-win situation can be achieved only through communication, learning, scientific training of employees, and realization of employee appreciation and value-maintenance. Therefore, it is very necessary for enterprises to train employees, and enterprises shall establish suitable talent training system according to actual conditions to provide continuous talents for enterprises[11].

Talent recruitment. In case enterprise interior faces talent shortage, external recruitment is the most direct and quickest method. Relative to employee training, effectiveness for external talent recruitments is stronger. In case there are vacancies in enterprises' posts, enterprise can promptly release recruitment information through websites etc., and they just need to wait specific post talents. But at the time of recruitment, some indecisive things may happen in enterprises. For 
example, misjudgement occurs at the time of grasping talents, which causes improper talent selection[12]. Therefore, enterprises need to strengthen investment in talent recruitment, accurately predict market change, and reduce some unnecessary costs as much as possible. Besides, talent competition of enterprises is the quality competition of related recruitment personnel, recruiters are the external image of enterprises, and they are the first person to contact talents at the same time. In case enterprise conditions are good, but recruiters lack corresponding recruitment qualities, enterprise image will be greatly reduced to lower attraction of enterprise to talent. Therefore, at the time of conducting recruitment, enterprise shall strictly select recruiters, and corresponding working specification shall be formulated at the same time to improve the core competitiveness of enterprises[13].

Culture construction of enterprises. Enterprise culture represents the voice of employees, and it forms during the continuous development of enterprise. In case talents are advantageous resources to enterprises, cultural construction is the soul of enterprises. So-called enterprise culture construction is the process for enterprises to continuously find problems. In case enterprises want to improve competitiveness and employees' enthusiasm, it shall be started from consideration for enterprise culture construction. For example, for "safety first", enterprises need to formulate corresponding safety management system. In a word, enterprise culture construction is not posturing, but is subject to enterprise development direction as target. Through cultural construction, employee value shall be realized, and the objective of enterprises to retain talents and increase cohesion can be realized[14].

Under some social economic condition, enterprise culture formed through practice is the sum for common consciousness, professional ethics and code of conduct etc. of enterprise staff. It can solve problems faced by enterprises during development. Therefore, effective sharing is conducted by organized members, and enterprise culture is the core proposition of enterprises. Integrating human capital into enterprise culture construction is able to effectively uniform employee pursuit and enterprise objective. Therefore, at the time of conducting cultural construction of enterprises, internal driving force of employees shall be activated through cultural ideas, and employees shall be permanently affected at the same time to make enterprises and human capital combine and promote annual enterprise development.

\section{Conclusion}

In a word, with the development of economy globalization, market competition starts to become increasingly fierce, and sustainable development of enterprise shall be conducted in virtue of human capital investment. In other words, human capital is the power and source of economic growth for enterprise, and human capital investment can promote enterprises to realize sustainable development. Under the era of knowledge economy, competitions between enterprises start to change into talent competition. The higher the comprehensive ability and professional energy saving of talents are, the greater the potential development brought to enterprises. Therefore, enterprises need to deeply understand the importance of human capital, strengthen investment strength, and promote economic growth.

\section{References}

[1] Du Xuefeng. Discussion on Relation between Human Capital Investment and Economic Growth of Enterprises[J]. Enterprise Reform and Management, 2017(16): 91.

[2] Yang Chengcheng. Discussion on Selection and Analysis of Modes for Human Capital Investment of Enterprise[D]. Ocean University of China, 2014.

[3] Jia Chaoli. Discussion on Relation between Human Capital Investment and Economic Growth of Enterprises[J]. Science and Technology Entrepreneurs, 2013(24): 218+220.

[4] Wang Qiang. Discussion on Relation between Strengthening Human Capital Investment and Economic Growth[J]. Economic Perspective (Journal at the end of Month), 2013(09): 140-141.

[5] Li Youde. Empirical Research on Relation between Human Capital Investment and Economic 
Growth[J]. Jianghan Tribune, 2012(02): 28-32.

[6] Wang Zhaoping, and He Jiajia. Empirical Researches on Different Human Capital Investment Modes and Economic Growth in Shaanxi Province[J]. Northwest Population Journal, 2011, 32(01): 48-52.

[7] Zhang Ling. Transformation of Human Capital Investment and Economic Growth Mode[J]. Scientific and Technical Information Development and Economy, 2010, 20(12): 115-116+131.

[8] Lu Limei. Discussion and Analysis on Relation between Human Capital Investment and Chinese Economic Growth Relation[J]. Periodical Per Ten Day for Management and Technology of Middle and Small-sized Enterprises, 2010(31): 134-134.

[9] Gao Ying. Discussion and Analysis on Contribution Rate of Human Capital Investment to Economic Growth in Liaocheng City[J]. Hebei Enterprises, 2017(1): 83-85.

[10] Chen Guangjiu. Researches on Relation between Human Capital Investment and Economic Development for Enterprises Based on Grey Relation Theory[J]. Journal Henan University of Technology (JCR Social Science Edition), 2013, 9(4): 85-89.

[11]Dai Xiangchao. Researches on Human Capital Investment, Organic Growth and Economic Development[J]. Northern Economy, 2011(4): 18-20.

[12] Li Jian and Yu Huixin. Researches on Relation between Human Capital Investment for Enterprise and Enterprise Performance[J]. China Labor, 2015(18): 78-82.

[13] Jiang Yanqiu. Theoretical Research on Influence of Human Capital Investment of Enterprise on Economic Benefit[J]. Knowledge Economy, 2012(2): 136-136.

[14]Liu Jiajia, and Deng Chengchao. Exploration of Strategy Of Human Capital Investment for Enterprises[J]. People's Tribune, 2015(8): 79-81. 